\title{
TRUSS HARBOR CRANES MODAL DESIGN ELEMENTS RESEARCH
}

\author{
Mariusz Żółtowski, Ph. D. \\ Michał Liss, Ms. C. \\ Bogdan Żółtowski, Prof. \\ Josef Melcer ${ }^{*}$, Prof. \\ University of Science and Technology, Poland \\ *) University of Zilina, Slovakia
}

\begin{abstract}
Dockside cranes must meet the relevant strength requirements that provide usefulness and not endanger the safety of their use. The vibration effect on structural safety hazard results from the impact of horizontal forces caused by the transport of goods for loading and transverse forces caused by wind, which can be dangerous for correct functioning. In addition, there are often serious effects of climate-related impacts of the environment, material fatigue, which actuates the degradation state of the object. Dynamic loads may therefor cause random effects that devastate the structures or lead to their catastrophic destruction.

Recognizing the need to improve the testing methods of crane structures in order to assess their condition and assess their safety factors - this paper attempts to develop a methodology for testing the degradation of the selected portion of a construction crane - using experimental modal analysis, realized in simulation tests in the Inventor environment as well as at test stand research.
\end{abstract}

Keywords: construction vibrations; state of degradation; modal analysis; stabilization diagram

\section{INTRODUCTION}

Dock crane operational loads (lifts) are most often random, making it difficult for an indirect assessment of changes in their dynamic state of condition for their safe use. Today, there is a tendency to shorten the time for determining the destruction status of the tested structure by giving up some difficult experimental studies in favor of computer simulations. Experimental studies are used to verify the simulation models by comparing the results of computer simulation and physical experiment. To determine the variation of loads, the dynamic models as a system of rigid bodies are used, in which operating conditions of work of these structures are simulated $[4,7,9,14]$.

In the method of measurement for determining the variable load, waveforms of acceleration or deformation at selected points of the structure are recorded, that are a response of the system to operational loads. Direct measurement of operational loads is very difficult and expensive, and often almost impossible. Often the determination of operational loads is carried out indirectly by means of computer simulation of a structure model, in which values are taken of the measured waveform of model answers at points corresponding to the measuring sensors on the structure $[1,2,3,5]$.

The dynamics of truss design elements has been described and verified in part in research of this work using techniques of modal analysis. Modal analysis is widely used in the study of damage caused by vibration, structural modification, update of the analytical model, control of the state and is also used to monitor vibration in aerospace structures and mechanics of civil engineering $[6,15,17,22]$. Often already used in various applications, modal analysis is a technique for the study of dynamic properties of some elements, using modal model parameters, consisting of modal frequencies, damping and vibration shapes [17,25].

This paper presents the dynamical properties of structural elements of port crane test procedure, taking into account the simulation tests and their verification at test stand. The analysis results of simulation studies using theoretical modal analysis in Inventor computational environment for the selected truss fragment, which is an equivalent to the components used in the construction of port cranes, had been verified at test stand using this experimental modal analysis $[5,17,23]$.

\section{VIBRATION IN CONSTRUCTION DISCRIPTION}

One of the basic criteria used in the design of modern crane construction is its dynamic properties. They have a direct impact on the vibration level, emitted noise, fatigue strength and stability of the structure. Analysis of dynamic properties, in most cases encountered in practice is made on the basis of the behavior of the construction model $[8,10,17]$, as studies of real objects is not always possible. Model design 
can be created in the process of transformation of analytical formalism used to describe the dynamics of the system, or on the basis of experiment results performed on the real object $[11,16,21]$. In the latter case the obtained function test object (of any structure), which is a function approximating the results (measurement). This function has important practical significance, because it can be useful to optimize the test procedure (test conditions, the number of parameters, number of ii repetitions). It also has cognitive significance because it can be transformed into a functional model of the object by means of adequate logical reasoning, using deductive methods. Such a model should reliably (adequately) reflect the construction answers (stress, displacement) treated by any dynamic load. The dynamic load is a load which value, direction, turn or touchdown place change over time $[12,18,23]$

The study pointed out such major problems occurring at the design stage of construction, as:

- determination of static and dynamic loads acting on individual nodes and elements of design,

- determine the stress distribution in selected areas of computed design,

- $\quad$ selection of the most loaded elements and to estimate their strength and durability (operational reliability).

Particular attention was paid to determine the course of the nature of the change and the value of extreme dynamic loads in the proposed structure. This approach was deemed important because of the accuracy of the designation of the status of the load depends the correctness of the design calculations, and as a result the reliable operation, as well as operational advantages (durability, running costs) and the cost of fabrication.

The basic step in analyzing the dynamics of an object is usually the determination of frequency vibrations of structural elements (i.e. the spectrum of vibration test pieces or set). Typically it is observed that random vibrations with these frequencies in the structure are subject to rapid dampening. But there is always the risk of a build-up of vibration, when external impacts (deterministic or random) in their structure may also include forcing frequencies close to the natural frequency of the structure.

The most dangerous states of dynamic loads associated with the extreme values of the stresses arise in the area of resonant vibration, the lowest frequencies of own construction. Such conditions may occur, for example: during a high-speed (displacement) in the environment of construction of climate impacts, wind, temperature, or passing vehicles. Usually occurring at the change in load structure nodes are transient processes of a fading amplitude [14,19].

With this in mind to determine the structure of dynamic loads, methods of their physical and mathematical modeling were applied - Fig.1. Methods of physical modeling were used for the test structural models at laboratory stands and during specially prepared polygon tests. Laboratory tests allow for a significant reduction in the duration of the experiment in relation to polygon testing. It is also easier to keep the repeatability of test conditions [3.22].
To describe the dynamics of construction, structural models were used, which were built in accordance with the finite element method. However, models constructed this way, in particular for the purpose of dynamic analysis, gave approximate results which use is very limited. They require some fine tuning on the basis of knowledge of the properties measured on the real object [17].
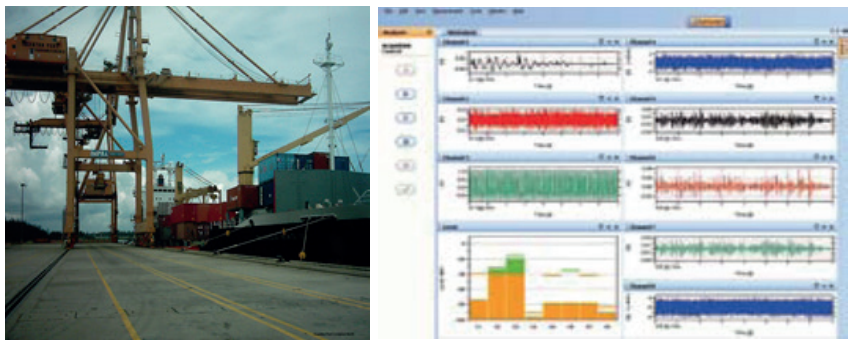

Fig.1. View of port crane and recording results of the dynamic state of using vibration

The model allowed determination of structural modal model which is a set of natural frequencies, damping factors and their corresponding vibration shapes - by use of suitable coordinate transformation model. Modal model can be further identified on a real object on the basis of identification experiment [6.22].

Use of the information contained in the vibration image (described by estimators determined vibration) of the desired fragment or the whole building structure is the concern of structural vibration diagnostics. In this area was the main issues of the presented study have been located [3.23].

In this study the vibration signal is the basis for the study of destruction specific port construction and many ancillary procedures for solving the task at excelling in the field of vibration engineering construction. In this paper information in the field of vibration will be recalled many times further in the text, particularly in the description and acquisition of signals, determining the vibration estimators and statistical processing of results for the destruction of selected studies of mechanical structures or parts (elements) of building structures [23].

System vibrations arising from violations of the equilibrium position of an object under the influence of: the elastic forces, the forces of gravity or friction, which are free vibrations have been studied for system with one degree of freedom. It is assumed here that violation of the equilibrium position is characterized by initial conditions: the initial position $\mathrm{x}_{0}$ and initial velocity $\mathrm{v}_{0}$. He the simplest model of an examined the technical system was considered - a system which has one degree of freedom (one mass $\mathrm{m}$ ) and has linear characteristics of elasticity (k) and damping (c) - Fig.2, and a harmonic driving force $\mathrm{F}(\mathrm{t})$ works on it. The equation of motion is expressed as the formula:

$$
m x+c \stackrel{*}{*}+k x=F(t)
$$

It shows that the systems' with one degree of freedom own vibration with are completely determined by the vibration frequency. The amplitude of the vibration depends on the 
initial conditions, and the own frequency and the oscillation period of them are independent.
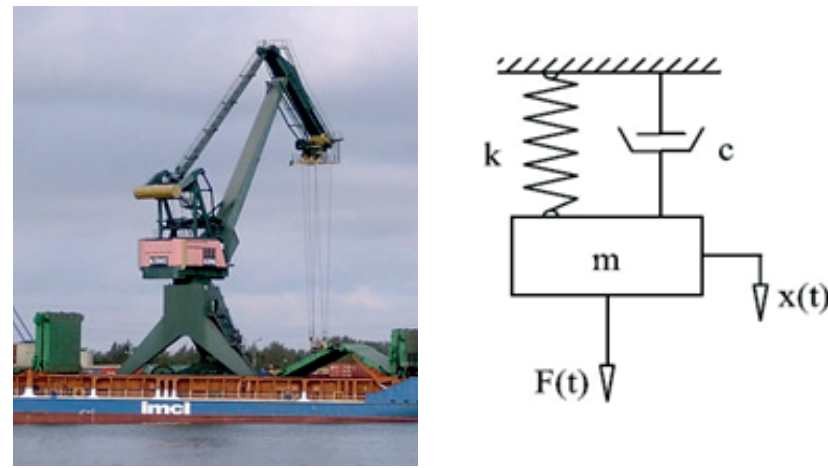

Fig.2. View of the crane, as an object of the modeled system with one degree of freedom

The parameters appearing in the description (1) of the model $\dddot{\mathrm{x}}, \dot{\mathrm{x}}, \mathrm{x}$ - are the process parameters of the vibration $(\mathrm{a}, \mathrm{v}, \mathrm{x})$, which argues that the vibration describe the state of the structure well.

In the low frequency range, the structures can be modeled by discrete systems with several degrees of freedom, and often with one degree of freedom. Therefore, it is assumed that, in practice, the system shown in Figure 2 may also be a model of $[6,22]$ :

- a construction machine of mass m on shock absorbers $(\mathrm{k}, \mathrm{c})$ attached to the foundation of high molecular weight.

- $\quad$ working machine (vehicle) of mass m on shock absorbers $(\mathrm{k}, \mathrm{c})$ moving on the ideally flat way,

- high building construction (cranes, chimneys, towers) exposed to the wind force.

In the first approach, these research objects can modeled by a system with one degree of freedom, and its properties looked up by mathematical description and analysis of the equations describing it, examine them in the way of measuring the parameters of vibration $(\ddot{\mathrm{x}}, \dot{\mathrm{x}}, \mathrm{x})$, which as a result of solutions describe a mathematical model interchangeably describe the same property, but from the side of the measuring system vibrations. In industrial practice, vibrations are commonly measured, avoiding complicated theoretical considerations $[17,22]$.

During operation of the afore mentioned structures, due to the existence of a number of external factors (environments enforcement, forces of other structures) and internal (aging, wear and tear, elements co-functioning) followed by disorders of equilibrium states, which propagate in the elastic center - material which is used to build the structure in question. These disorders are dynamic and keep the conditions of equilibrium between the state of inertia, elasticity, damping and extortion. As a result, this causes the dissipation of energy of waves, the diffraction, dampening, and overlap. The existence of the sources and the spread of disorder causes the vibration of structural elements and the surrounding environment [22]. These phenomena have been mapped in the vibrational interaction model presented further.

As a result of the existence of the input and execution states representing transformation processes taking place in the structure, a number of symptoms (signs) is formed giving a measure contained in the processes starting from the structure. These processes are also the basis for building a model of signal generation, determining the method of construction, operation and description of changes in the destruction of the object [6.17]. Features of the transition vibration signals model for structures subject to random distortions are based on assumptions:

- condition of the structure is determined uniquely by the characteristic signal $\varphi_{i}(t, \theta)$, generated separately with each forcing. This signal changes over dynamic time (short) " $t$ " and the evolution in their spare time (long) , $\theta$,.

- characteristic signal is comprised of a determined process $\varphi_{\mathrm{o}}$ and random $\mathrm{n}$, and its intensity change condition is characterized by destruction of the structure.

- the transformed characteristic signal which is a mapping of internal interactions - the degradation of structure - is perceived as $y(t, \theta)$ and in the simplest case is the response of the test structure element of the characteristics $h(t, \theta)$ to force $x(t, \theta)$. Considering the vastness of space (dimensions) the " $r$ " of the construction of such a signal can be written as:

$$
\mathrm{y}(\theta, \mathrm{r})=\sum_{i=1}^{\infty} \varphi_{\mathrm{i}}(\mathrm{t}, \theta, \mathrm{r}) * \mathrm{~h}(\mathrm{t}, \theta, \mathrm{r}) * \delta(\mathrm{t}-\mathrm{iT})
$$

- $\quad$ output processes from the construction (selectively) influence back upon the processes of destruction and continually on the state of the building (element) by the positive disruptive feedback, distorting the original signal $\varphi_{\mathrm{i}}(\mathrm{t}, \theta)$.

- for a fixed value of operational time $\theta_{i}=$ const all building objects are treated as linear and stationary systems, which properties are described by the impulse response $\mathrm{h}(\mathrm{t}, \theta, \mathrm{r})$ or their transforms: Laplace operator $\mathrm{H}(\mathrm{p}, \theta, \mathrm{r})$ or Fourier spectrum $\mathrm{H}(\mathrm{j} \omega, \theta, \mathrm{r})$.

The described sequence of the assumptions leading to signal generation model are shown in a block diagram form in Figure 3.

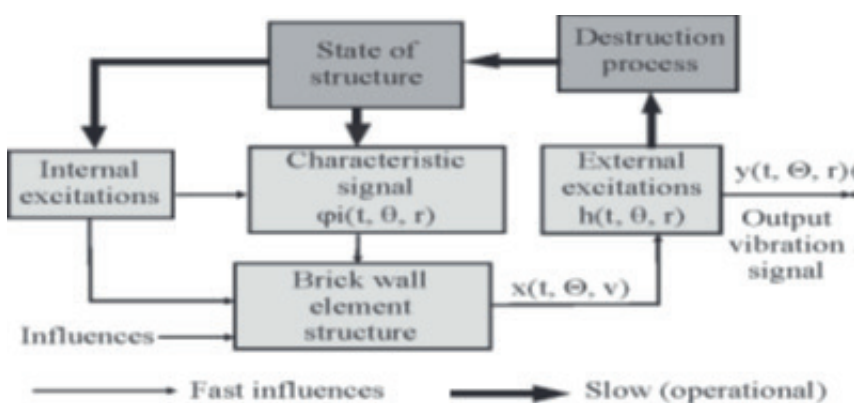

Fig. 3. Block diagram of the signal pass through the construction test piece

The modeling assumes that the vibration signal output from any point of receipt may be expressed by the formula [6.22]:

$$
y_{k}(\Theta, r)=\sum_{i=1}^{k} a(k) h_{i}(t, \Theta, r) *\left[u_{i}(t, \Theta, r)+n_{i}(t, \Theta, r)\right]
$$


where:

- $\quad$ impulse transition function $\mathrm{h}\left({ }^{*}\right)$ taking into account the destruction properties of the material,

- $\quad \mathrm{a}(\mathrm{k})$ gives different summation weight related to the place of receipt " $r$ "

Presented in the form of equation (3) the method how to interpret the output signal $y(t, \theta, r)$ is true in the general case of excitations of objects of timed period work, but not always so simple as in figure 4 , which shows the formation of random excitations from the effects of wind on high buildings, chimneys, towers and recording responses in the form of a complex vibration signal.

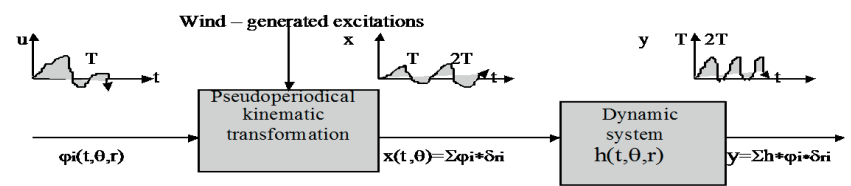

Fig. 4. Schematics of the characteristic signal transformation $\left.\varphi i^{*}\right)$ for the output signal $y\left({ }^{*}\right)$ as a generation model of the signal in buildings by environmental forcing[6]

The modeling also takes into account the fact that the received signal output anywhere in the design is a weighted sum of the answers to all elementary events $\varphi \mathrm{i}(\mathrm{t}, \theta, \mathrm{r})$, always occurring in the same sequence at specific points on the pulse of the dynamic transfer function $h(t, \theta, r)$. These effects add up and are further transformed along different axes of reference, with the change of signal reception " $r$ " is also connected with the change of the transmittance.

The designed vibration signal transition thru the test piece of the structure model has been described by the FRF function - marked out in experimental modal analysis, as the ratio of excitation of vibration force at the input to the amplitude of the vibration acceleration on the output. The inversion of FRF function is transmittance $\mathrm{H}(\mathrm{f})$, defined as the ratio of response to force [6.23].

The indicated properties of the created vibration processes thru researched structures transition model have been used further to assess changes in the degree of degradation of the structure part, by examining the transition vibratory signals through the various structures of the modeled components or units of the structure.

\section{IDENTIFICATION OF CONSTRUCTION STATE}

The aim of the dynamics study of a complex system of lifting structure is to assess the dynamic loads, reflecting the state of degradation and predict the correct behavior time of the system. With the increase of load, increased requirements for durability and reliability, as well as in many cases the need for non-deconstructional assessment of degradation, the importance of analyzing structural dynamics increases [6.23]. Changes in the degradation of the construction of buildings reported by a vibration signal reflect in fluctuating levels of vibration or a change in transmittance, or FRF from the point of extortion to the collection point.
Quality tests of degradation the state is carried out using the methods of identifying, using the assessment of changes, respectively, resonance frequency, amplitude and attenuation coefficients in those frequencies.

For complex systems, often nonlinear, for the purpose of identifying the degradation of construction - modal analysis is used. As a result of its implementation, the modal model based on stabilize diagram is obtained, which is an ordered set of own rates, the corresponding coefficients of damping and own vibration shapes. Based on the knowledge of modal model the object response can be predicted for any disorder in both time and frequency domains $[17,25]$.

Modal model parameters allow the decoupling of equations describing vibrations of the system, and their values are determined from the relation $[17,23]$ :

$$
m_{r}=\frac{1}{2 j \varpi_{r} R_{i r}} \quad k_{r}=\varpi_{n r}^{2} m_{r} \quad c_{r}=2 m_{r} \varpi_{r n} \delta_{m}
$$

These values describe the properties associated with $\mathrm{r}$ - the own frequency and changes of the own frequency depend directly proportional to the amount of change of stiffness or mass, and also depend on the place of failure increase in the structure $[17,22,23]$.

In practice, the following types of modal analysis are distinguished[17]:

- theoretical, which requires the solution of its own issue for the adopted structural model of the object;

The theoretical modal analysis is defined as an own matrix problem, depending on the mass matrix, rigidity and damping. Theoretical modal analysis requires addressing the own issue for the adopted structural model of the tested structure [13,21]. Designated collections of own frequencies, the damping factors for own frequencies and forms of own vibrations allow the simulation of structural behavior at any extortion, selection of controls, construction modifications and other.

The analysis of own frequencies and own vectors is obtained from the equations of motion (after skipping the matrix containing the damping parts and the vector of external loads). Then, the equation of motion vibrations is as follows:

$$
B \ddot{q}+K q=0
$$

In reference to a system with one degree of freedom, the solution has the form of a function:

$$
q(t)=\vec{q} \sin \varpi t+(\varphi)
$$

where $\vec{q}$ : - amplitude vector of own vibrations

After inserting the above equation, and the second derivative into the equation of motion, the following is obtained:

$$
\left(-\varpi^{2} B+K\right) \vec{q} \sin (\varpi t+\varphi)=0
$$

The above equation must be fulfilled for any time $\mathrm{t}$ - then this gives a system of algebraic equations: 


$$
\begin{gathered}
\left(K-\varpi^{2} B\right) \vec{q}=0 \\
\left(k_{11}-\omega^{2} m_{11}\right) q_{1}+\left(k_{12}-\omega^{2} m_{12}\right) q_{2}+\cdots+\left(k_{1 n}-\omega^{2} m_{1 n}\right) q_{n}=0 \\
\left(k_{21}-\omega^{2} m_{21}\right) q_{1}+\left(k_{22}-\omega^{2} m_{22}\right) q_{2}+\cdots+\left(k_{2 n}-\omega^{2} m_{2 n}\right) q_{n}=0 \\
\cdots \cdots \cdots \cdots \cdots \cdots \cdots \cdots \cdots \\
\left(k_{41}-\omega^{2} m_{41}\right) q_{1}+\left(k_{42}-\omega^{2} m_{42}\right) q_{2}+\cdots+\left(k_{n n}-\omega^{2} m_{n n}\right) q_{n}=0
\end{gathered}
$$

It created a homogeneous system of linear algebraic equations, which has a nonzero solution only if:

$$
\operatorname{det}\left(K-\varpi^{2} B\right)=0
$$

Multiple roots may appear among roots and a vector formed by a set of frequencies in order of increasing values is called the frequency vector. The first frequency is called the fundamental frequency [21].

$$
\varpi=\left[\varpi_{1}, \varpi_{2} \ldots \varpi_{n}\right]
$$

Theoretical modal analysis is used mainly in the design process, when there is no option of studies on the given object.

- experimental requiring controlled identification experiment, during which oscillation of the object is forced; the force and the response in one or a plurality of points arranged on the examined object is measured;

Identification experiment in experimental modal analysis (Fig. 5) involves forcing the vibration of an object with a modal hammer and simultaneously measuring the exciting force and system response, usually in the form of the spectrum of vibration acceleration.

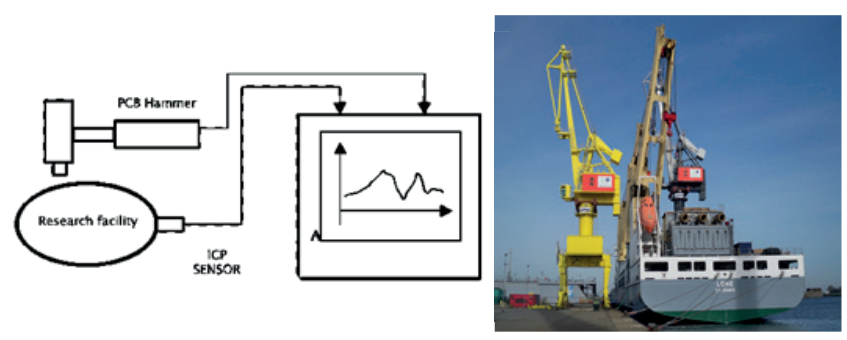

Fig. 5. The essence of research in experimental modal analysis

The modal model (natural vibration frequencies, vibration and damping forms) is obtained from the stabilization diagram and software presented vibration form animation. These data allow to determine the characteristic frequencies of vibration which are subject to fluctuations during the degradation state while in use and that indicates the progress of the processes of destruction of the structure.

- $\quad$ operational, based on operational experiment, in which measurements are made only for system response in a number of measurement points, while the movement of the subject is due to the actual operating extortion.

It is used to identify objects of large-scale spatial dimensions and large masses, and is based on the measurement of the response to the operating force, as a result of external forces (picture 6), or kinematic extortion and the process of destruction of building elements [22,25].

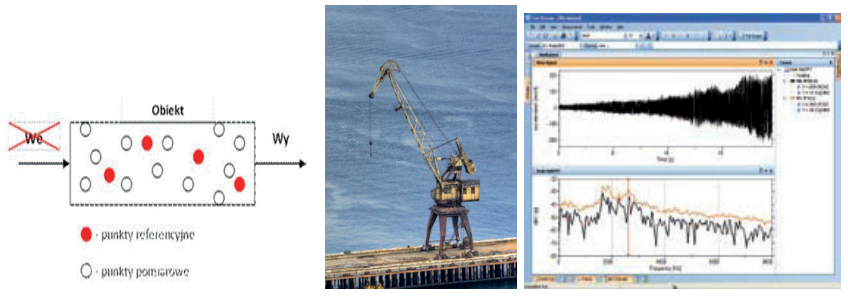

Fig. 6. The essence of operational modal analysis

Operational modal analysis:

- allows for modal analysis of large-sized objects, for which the laboratory tests would be difficult to implement.

- modulates objects correctly as extortions correspond to the actual loads due to their time span, spatial distribution, amplitudes and boundary conditions.

In practical use so far, operational modal analysis was used to diagnose trusses (masts, antennas, cranes), the diagnosis of turbine set and to diagnose the quality of bridge structures. In most of these applications, it is assumed that as a result of damage, locally structural rigidity changes, which causes changes parameters of the modal model. By tracking changes of vibration forms, an area can be specified in which there is significant destruction [17].

\section{THE ANALITICAL TOOL IN THE AUTODESK INVENTOR ENVIRONMENT}

Modal studies aim to determine dynamic properties of truss elements commonly used in the construction of harbor cranes to indicate possible opportunities to diagnose and even modify these properties through structural changes, which would ensure high durability of these objects.

To perform a modal analysis of truss design, a threedimensional model of its selected fragment was created. Truss structures consist of appropriate types of profiles or separable/inseparable connected links profiles. Selected truss fragment of harbor cranes model was done (in the Inventor software), which has been joint with geometric relations, according to the nature of the interaction between these elements. Such created system was analyzed by the module "Stress Analysis". This analytical module is equipped with a possibility of using the finite element method in order to improve theoretical modal analysis. Preparations preceding calculation step include:

- defining how to support the test piece,

- conversion of the bonds resulting from the assembly and method of assembling the various elements to determine the number of vibration forms.

Depending on the type of connection present between the elements of the construction bonds they have been replaced by so-called contact bond for static connections and spring-type contacts for flexing connections. Contact bond is related to bonding material equivalent to combined elements such as.: welds. In contrast, the spring-type contact 
bond allows you to enter between adjacent surfaces a no elastic mass element of stiffness ratio which is determined by the user. When modeling, the phenomenon of damping in the case of flexing connections is omitted, with the result that the model is greatly simplified. Fig. 7 shows the actual and modeled portion of the construction crane model tested using theoretical modal analysis.
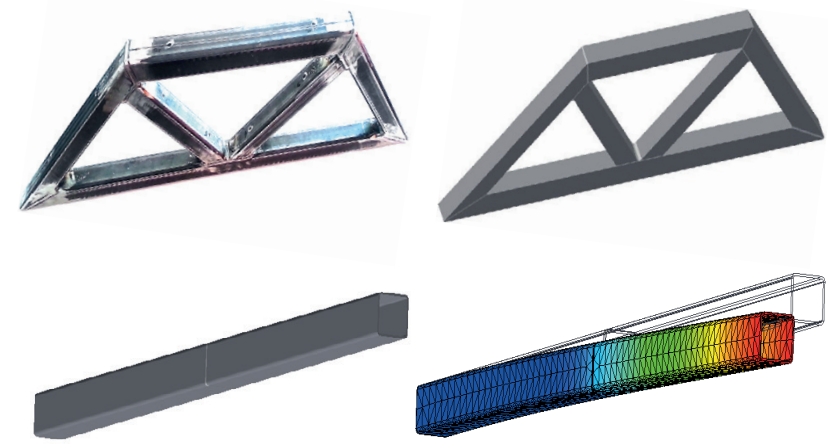

Fig. 7. Actual and theoretical model of the tested truss element

The fragment of the construction crane created in such a way in the Inventor environment was subjected to simulation calculations, which generate a report containing information about the task analyzed and simulation results are presented in a graphical form. The results are presented in the form of layering maps, graphically depicting forms of free vibration of a tested segment, along with an array containing frequency values corresponding to the measured vibration forms. The program also allows to carry out animation of obtained deformations that occur during the free vibration of each of the observed forms.

\section{RESEARCH RESULTS}

In the framework of the implementation of theoretical calculations using the method of modal analysis, characteristic vibration frequencies were generated for a given segment of a lifting structure, which are summarized in Tab.1. During the simulation, the number of designated natural frequencies was limited to 20 .

Tab. 1. Frequency of own vibrations generated using theoretical modal analysis

\begin{tabular}{|c|c|c|c|c|c|c|c|c|c|}
\hline F1 & F2 & F3 & F4 & F5 & F6 & F7 & F8 & F9 & F10 \\
\hline$[\mathrm{Hz}]$ & {$[\mathrm{Hz}]$} & {$[\mathrm{Hz}]$} & {$[\mathrm{Hz}]$} & {$[\mathrm{Hz}]$} & {$[\mathrm{Hz}]$} & {$[\mathrm{Hz}]$} & {$[\mathrm{Hz}]$} & {$[\mathrm{Hz}]$} & {$[\mathrm{Hz}]$} \\
\hline 71,29 & 289,40 & 345,10 & 350,83 & 792,55 & 904,46 & 995,99 & 1063,37 & 1063,84 & 1168,01 \\
\hline $\mathrm{F} 11$ & $\mathrm{~F} 12$ & $\mathrm{~F} 13$ & $\mathrm{~F} 14$ & $\mathrm{~F} 15$ & $\mathrm{~F} 16$ & $\mathrm{~F} 17$ & $\mathrm{~F} 18$ & $\mathrm{~F} 19$ & $\mathrm{~F} 20$ \\
\hline$[\mathrm{Hz}]$ & {$[\mathrm{Hz}]$} & {$[\mathrm{Hz}]$} & {$[\mathrm{Hz}]$} & {$[\mathrm{Hz}]$} & {$[\mathrm{Hz}]$} & {$[\mathrm{Hz}]$} & {$[\mathrm{Hz}]$} & {$[\mathrm{Hz}]$} & {$[\mathrm{Hz}]$} \\
\hline 1273,96 & 1373,37 & 1577,62 & 1702,82 & 1814,78 & 1847,73 & 1930,23 & 2076,51 & 2290,80 & 2357,98 \\
\hline
\end{tabular}

Frequency and forms of own vibrations resulting from simulation allow to identify the most dynamically vulnerable areas of a given construction segment. This knowledge can be used to modify the test structure to improve its rigidity in sensitive areas. This information also can be used to determine the current technical condition of the structure and in the case of knowledge of previous states it is possible to develop and implement appropriate diagnostic procedures. A few examples of the form of vibrations have been graphically presented below.

Figure 8 presents the first embodiment of a vibration form at a frequency of $71.29[\mathrm{~Hz}]$. Vibration at low frequencies reflecting the focus maximum energy of destruction should be of particular interest to engineers. They usually have a very significant impact on the durability of the whole construction. In the case of the analyzed object that was left-restrained, the embodiment of these vibration has bending characteristics.

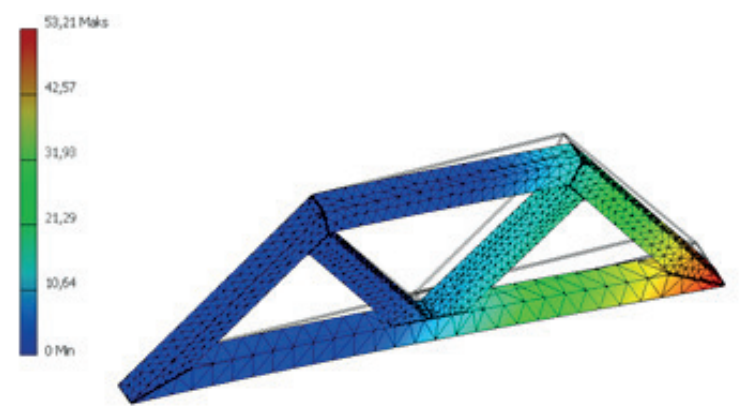

Fig. 8. The bending vibrations of the truss welded at a frequency of $71.29[\mathrm{~Hz}]$

Truss structures in theory are treated mostly as a type of thin-walled structures. In these constructions, in addition to the bending stresses occur much more dangerous stresses derived from a constrained torsion, also called sometimes a bimoment. Therefore, in the case of such structures, own vibrations of torsion or torsion - flexural nature are more important. Usually such forms of vibration of this nature occur in slightly higher frequencies - fig.9.

The first form of vibrations of a torsion - flexural nature occurs at a frequency of $1000[\mathrm{~Hz}]$. This form can be triggered by both the normal stress of which constrained twisting may appear, as well as touching, which can be induced by transverse forces (shear) or torque.

The free twisting of steel profiles can be defined as a certain deformation, by which the distance of the two sections before and after the deformation is the same. This would mean that the elongation of individual fibers and longitudinal stresses are zero.

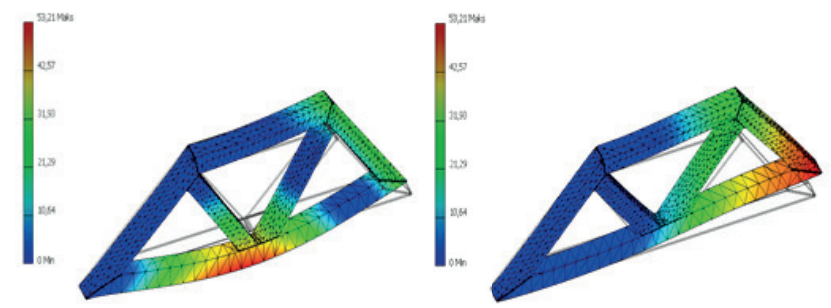

Fig. 9. Examples of two following forms of own vibrations of the truss structure of a flexural frequencies sequentially $289.40[\mathrm{~Hz}]$ and $345.10[\mathrm{~Hz}]$ 
The situation is different in the case of a constrained torsion, wherein the distance between the cross-sections before and after deformation is different, and the longitudinal fibers change their original length - figure 10. In the analyzed example, it was not observed among 20 normal own vibration forms, such ones representing torsion or torsion - flexural form similar to the definition of non-constrained twisting.

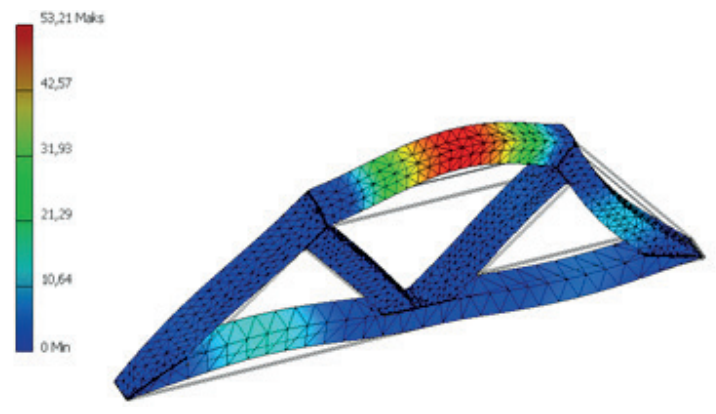

Fig. 10. The first embodiment of a torsion - flexural vibration form at a frequency of $995.99[\mathrm{~Hz}]$

The precise analysis of natural own vibration forms provides very thorough knowledge of the dynamic state of technical objects, which requires a combination of knowledge from several other fields of technical sciences - particularly the principles of diagnosing the machinery state [22].

The need to verify the results of simulation studies on a real piece of truss model (Figure 8 ) justifies the need to identify the best way of suspension of truss during the modal experiment, to limit the number of degrees of freedom. The completed studies looked at four different approaches to suspend an object of research in experimental modal analysis, the essence of which represents Fig.5. The adopted solutions analyzed in the active experiment $[22,25]$ are:

a) object suspended on the fishing line,

b) the object suspended on luggage cords (fig. 11)

c) the object suspended on chains,

d) object suspended on chains with rubber elements.

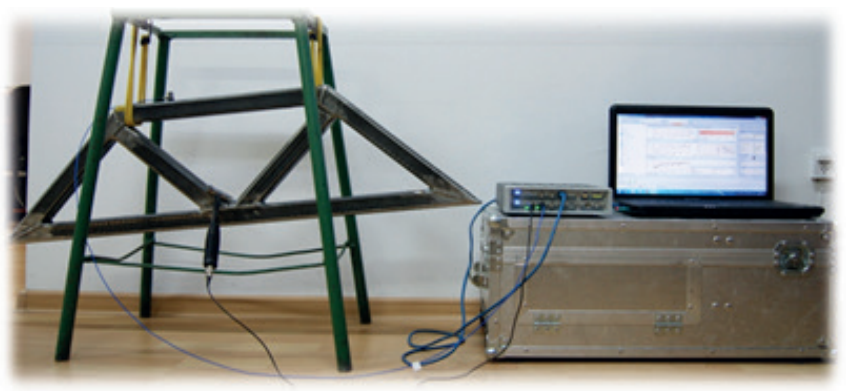

Fig. 11. Schematic view of a truss suspended on luggage cords

The test results were evaluated using the AutoMAC coefficient [17] and analysis of the various own vibration forms, enabling selection of the best modal parameters of individual types of suspension. The results of the tested methods of suspension are summarized in Table 2.
Tab. 2. Summary of modal parameters for the test cases of the suspended test object

\begin{tabular}{|l|c|c|c|c|c|c|c|c|}
\cline { 2 - 9 } \multicolumn{4}{c|}{} & \multicolumn{9}{c|}{ Modal parameters } & \multicolumn{2}{c|}{ Solution D } \\
\cline { 2 - 9 } \multicolumn{1}{c|}{ Solution A } & \multicolumn{2}{c|}{ Solution B } & \multicolumn{2}{c|}{ Solution C } & \\
\cline { 2 - 9 } & Frequency & Damp. factor & Frequency & Damp. factor. & Frequency & Damp. factor & Frequency & Damp. factor \\
\cline { 2 - 9 } & {$[\mathrm{Hz}]$} & {$[\%]$} & {$[\mathrm{Hz}]$} & {$[\%]$} & {$[\mathrm{Hz}]$} & {$[\%]$} & {$[\mathrm{Hz}]$} & {$[\%]$} \\
\hline Form 1 & 279.463 & 0,00 & 281.230 & 0,02 & 280.402 & 0,03 & 280.222 & 0,10 \\
\hline Form 2 & 752.122 & 0,03 & 747.881 & 0,26 & 740.045 & 0,10 & 756.716 & 0,59 \\
\hline Form 3 & 1405.607 & 0,05 & 1406.599 & 0,29 & 1022.556 & 0,04 & 1405.092 & 0,14 \\
\hline
\end{tabular}

The results were compared with results of simulation studies derived from modal analysis done in Autodesk Inventor software. Tab. 3 summarizes the results with the percentage of showing the difference in the results obtained in simulation and experiments. Based on these results it can be concluded, that the impact of the suspension on the method of measurement results obtained in most of the analyzed cases does not have so much significance.

Tab. 3. Summary of results and Autodesk Inventor software results

\begin{tabular}{|c|c|c|c|c|c|c|c|c|c|}
\hline & \multicolumn{9}{|c|}{ Modal parameters } \\
\hline & \multicolumn{2}{|c|}{ Solution A } & \multicolumn{2}{|c|}{ Solution B } & \multicolumn{2}{|c|}{ Solution C } & \multicolumn{2}{|c|}{ Solution D } & \multirow{2}{*}{$\begin{array}{l}\text { Inventor } \\
\text { Frequency }\end{array}$} \\
\hline & Frequency & Difference & Frequency & Difference & Frequency & Difference & Frequency & Difference & \\
\hline & {$[\mathrm{Hz}]$} & [\%] & {$[\mathrm{Hz}]$} & [\%] & {$[\mathrm{Hz}]$} & {$[\%]$} & {$[\mathrm{Hz}]$} & {$[\%]$} & {$[\mathrm{Hz}]$} \\
\hline Form 1 & 279,46 & 0,14 & 281,23 & 0,49 & 280,40 & 0,19 & 280,22 & 0,13 & 279,86 \\
\hline Form 2 & 752,12 & 0,06 & 747,88 & 0,50 & 740,05 & 1,54 & 756,72 & 0,68 & 751,64 \\
\hline Form 3 & 1405,61 & 1,05 & 1406,60 & 0.98 & 1022,56 & 28,02 & \begin{tabular}{ll|}
1405,09 \\
\end{tabular} & 1,09 & 1420,55 \\
\hline
\end{tabular}

All received and selected modal parameters describe the analyzed object at good degree. The only exception is the solution $\mathrm{C}$, which makes it impossible to enforce all forms of vibrations. In further studies of this work, carrying out research using experimental modal analysis, research object was suspended on the fishing line.

Experimental verification obtained in simulations for the indicated model frequencies and form shapes was realized in the idea shown in Figure 12.

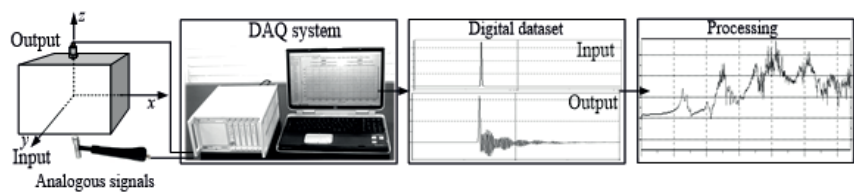

Fig. 12. The idea of determining the parameters of the dynamic crane construction

For the measurement waveforms of extortion and system response times of the studies system and defining the function of the FRF, LMS TEST.XPRESS companies measurement equipment was used. This software enables you to easily perform a modal analysis of structural elements, such as any building structures. The program has an easy and pleasant user-friendly interface - figure 13. 


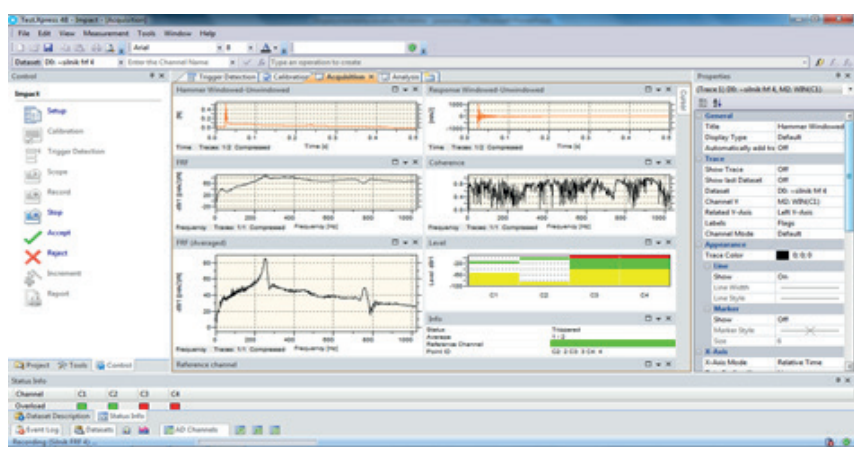

Fig. 13. The main dialog window during tests

In the model test of a truss fragment (Fig. 8) extortion and answers and programmatically determined FRF transition functions, as well as diagrams of stability were recorded. The acquired own vibration frequencies and these forms of vibrations were compared with the results of the theoretical modal analysis. Figure 14 shows an example of the results of the research function of the FRF, and Fig. 15 - a sample diagram of stabilization.
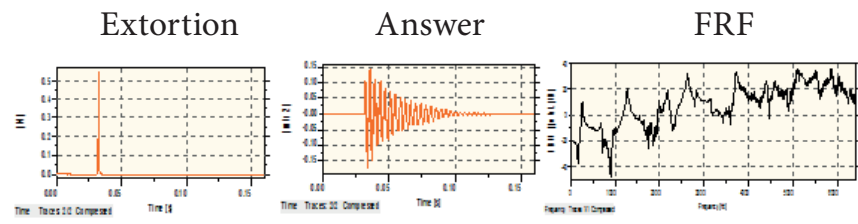

Fig.14. Timing of extortion, responses and FRF functions for the modeled construction crane fragment

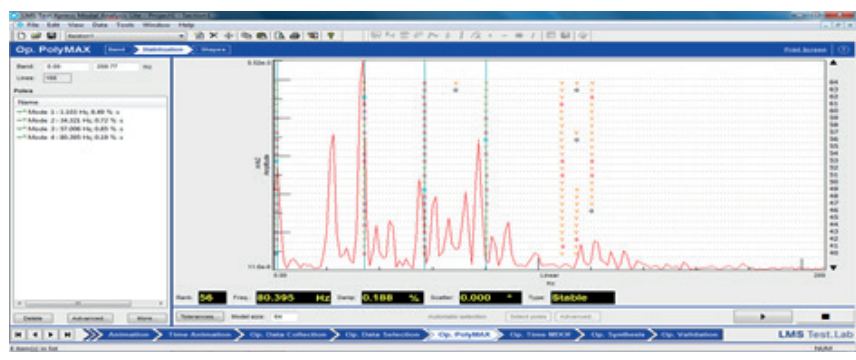

Fig. 15. Stability diagram for the modeled construction crane fragment

The results of theoretical modeling in simulation model and their researchs tand verification of the model of the truss, gives evidence to the research methodology of complex objects vibration modal analysis methods and form the beginning and preparation for a wider variety of real objects.

\section{FINAL CONCLUSIONS}

The search for methods of non-destructive testing of different port structures indicate the possibility of using modal analysis in the assessment of their degradation, which, for example, for a lifting structure are presented in this paper.
With different varieties available for forms of modal analysis, theoretical and operational modal analysis was used here in the study of destruction.

The results of preliminary studies point to the fact that it is possible to distinguish between material properties of a lifting structure, which has an impact on the ability to distinguish their mechanical properties. The study also confirmed the usefulness of Inventor software to recognize degradation using theoretical modal analysis performed on structural elements of modeled port cranes.

With the presented considerations and the results obtained, the following summary comments can be offered:

- $\quad$ resonance frequency for the modeled lifting element was generated,

- $\quad$ it was agreed that a change in working conditions for the lifting element causes an increase in the frequency of own vibration, which proves the usefulness of this method for the assessment of degradation in the quality of construction,

- the importance of a particular character of vibration form of the sensitivity debit lattice structure was highlighted.

The research results point to the fact that it is possible to distinguish between ownership of degradation in the crane structures, which affects the ability to assess threats and their mechanical properties. Stand and operational testing of equipment confirmed the usefulness of the LMS devices and the use of Inventor software to implement modal analysis at the actual building construction.

The practically verified susceptibility of modal analysis for the degree of degradation of a fragment of crane structures shows to the satisfaction of practical application, the differences between the functional and damaged structure. Thus, it becomes possible to determine the risks of building structures (port) on the basis of the study of the own vibration frequencies values and their form using modal analysis.

\section{BIBLIOGRAPHY}

1. Batel M.: Operational modal analysis - another way of doing modal testing. Sound and Vibration, August 2002.

2. Bishop R., Johnson D.: The mechanics of vibration. Cambridge University, Press, 1980.

3. Brandt S.: Data analysis ( in Polish). Wydawnictwo Naukowe PWN (Scientific Publishing House), Warszawa 1999.

4. Brown D., Allemang R.: Multiple Input Experimental Modal Analysis. Fall Technical Meeting, Society of Experimental Stress Analysis, Salt Lake City, UT, November 1983.

5. Brunarski L.: Non-destructive methods for concrete testing (in Polish). Arkady, Warszawa 1996. 
6. Cempel C.: Vibroacoustical Condition Monitoring, Ellis Ltd., Chichester, ᄀNew York, 1991.

7. Dzida M., Olszewski W.: Comparing combined gas tubrine/steam turbine and marine low speed piston engine/steam turbine systems in naval applications. Polish Maritime Research, No.4 (71), Vol.18, 2011.

8. Formenti D., Richardson M.: Parameter estimation from frequency response measurements using rational fraction polynomials (twenty years of progress). Proceedings of International Modal Analysis Conference XX, February 4-7, 2002, Los Angeles, CA.

9. Girtler J., Korczewski Z., Mańczak J.: Operational problems of large power diesel engines combusting biofuels, considered together with assessment of their operation. Polish Maritime Research, No 2 (65), Vol. 17, 2010 .

10. Ibrahim S., Mikulcik E.A.: Method for the direct identification of vibration parameters from the free response. Shock and Vibration Bulletin, Vol. 47, Part 4, 1977.

11. Peeters B., Ventura C.: Comparative study of modal analysis techniques for bridge dynamic characteristics. Submitted to Mechanical Systems and Signal Processing, 2001.

12. Pickrel C.R.: Airplane ground vibration testing - nominal modal model correlation. Sound and Vibration, November 2002.

13. Richardson M.: Is it a mode shape or an operating deflection shape? Sound and Vibration, February 1997.

14. Richardson M.: Structural dynamics measurements. Research Studies Press, Ltd. Baldock, Hertfordshire, England, December 2000.

15. Rudnicki J.: The evaluation of the vibration measurement usability of electronic indicator LEMAG „PREMET C”. Journal of Polish CIMAC, Vol. 7 No. 2, Gdańsk, 2012.

16. Shih C., Tsuei Y., Allemang, R., Brown D.: Complex mode indication function and its applications to spatial domain parameter estimation. Proceedings of International Modal Analysis Conference VII, January 1989.

17. Uhl T.: Computer-aided identification of mechanical structure models ( in Polish). WNT (Scientific Technical Publishers), Warszawa 1997.

18. Williams R., Crowley J., Vold H.: The multivariate mode indicators function in modal analysis. Proceedings of International Modal Analysis Conference III, January 1985.
19. Vold H., Schwarz B., Richardson M.: Display operating deflection shapes from non-stationary data. Sound and Vibration, June 2000.

20. Vold H., Kundrat J., Rocklin G.A.: Multi-input modal estimation algorithm for mini-computers. S.A.E. paper No. 820194, 1982.

21. Żółtowski B.: The investigations aid in exploitation. Liptowski Mikulesz. XI International Technical degradation Conference. ISSN 1642-347X-1, Słovakia, 2012.

22. Żółtowski B., Cempel C.: Engineering of diagnostics machines. PTDT, ITE - PIB, Radom, ISBN 83-7204-4147, 2004 s.1109.

23. Żółtowski M.: Modal analysis in the testing of building materials ITE-PIB, Radom 2011.

24. Żółtowski M., Żółtowski B., Castaneda L.: Study of the state Francis Turbine. Polish Maritime Research No. 2/2013, pp 32-38.

25. Żółtowski M.: Investigations of harbour brick structures by using operational modal analysis. Polish Maritime Research No 1/2014, pp 32-38.

\section{CONTACT WITH AUTHOR}

Mariusz Żółtowski

University of Science and Technology

Kordeckiego 20 St.

85-950 Bydgoszcz

Poland

e-mail: mariusz.zoltowski@utp.edu.pl

Josef Melcer

Katedra stavebnej mechaniky

Stavebna Fakulta

University of Zilina

Univerzitná 8215/1

01026 Žilina

Slovakia

e-mail: melcer@fstav.uniza.sk 